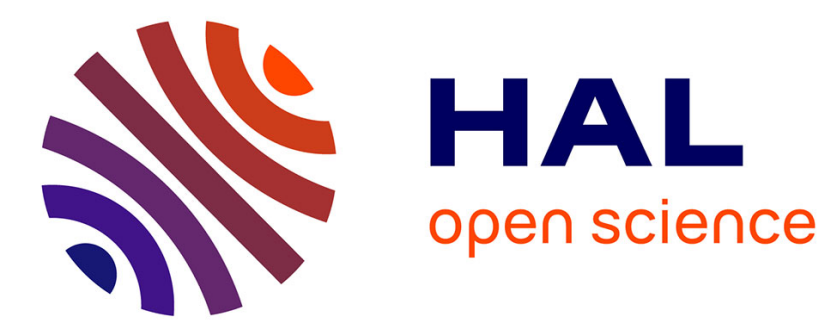

\title{
BAW Pressure Sensor on LiNbO3 Membrane Lapping
}

T. Baron, J. Masson, J.-P. Romand, S. Alzuaga, Lise Catherinot, Matthieu

Chatras, S. Ballandras

\section{To cite this version:}

T. Baron, J. Masson, J.-P. Romand, S. Alzuaga, Lise Catherinot, et al.. BAW Pressure Sensor on LiNbO3 Membrane Lapping. EFTF 2010, 24th European Frequency and Time Forum, Apr 2010, Noordwijk, Netherlands. 10.1109/EFTF.2010.6533644 . hal-00578951

\section{HAL Id: hal-00578951 \\ https://hal.science/hal-00578951}

Submitted on 15 Apr 2021

HAL is a multi-disciplinary open access archive for the deposit and dissemination of scientific research documents, whether they are published or not. The documents may come from teaching and research institutions in France or abroad, or from public or private research centers.
L'archive ouverte pluridisciplinaire HAL, est destinée au dépôt et à la diffusion de documents scientifiques de niveau recherche, publiés ou non, émanant des établissements d'enseignement et de recherche français ou étrangers, des laboratoires publics ou privés. 


\title{
BAW pressure sensor on $\mathrm{LiNbO}_{3}$ membrane lapping.
}

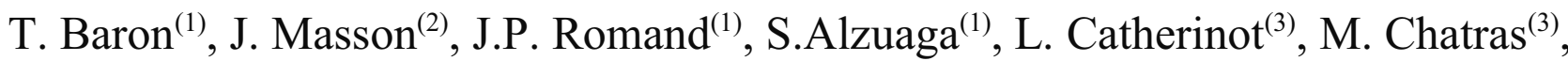 \\ S. Ballandras ${ }^{(1),(2)}$ \\ (I) FEMTO-ST, UMR CNRS-UFC-ENSMM-UTBM 6174, \\ ENSMM, 26 Chemin de l'Epitaohe, 25030 Besançon Cedex, France \\ (2) SENSeOR SAS, TEMIS Innovation, \\ Rue Alain Savary, 25000 Besançon, France \\ (3) Xlim, UMR 6172 CNRS-Université de Limoges \\ Limoges, France
}

\section{INTRODUCTION}

Single crystal-based acoustic resonators for pressure sensors have received a strong interest for many years. Various developments have been particularly achieved using Quartz and $\mathrm{LiNbO}_{3}$ with either SAW delay lines or resonators. However, most approaches have been developed exploiting $\mathrm{LiNbO}_{3}$ machining along standard etching, rarely compatible with batch processes as used for Micro-Electro-Mechanical Systems (MEMS). In this work, we propose a pressure sensor fabricated on compound $\mathrm{LiNbO}_{3} / \mathrm{Silicon} / \mathrm{Silicon}$ substrates obtained by $\mathrm{Au} / \mathrm{Au}$ bonding at room temperature and double face lapping/polishing of $\mathrm{LiNbO}_{3} /$ silicon stack and a final gold bonding with a structured silicon wafer. This approach allows for a collective and accurate production of sensors, the sensor sensitivity being controlled by the membrane thickness and diameter.

BAW devices submitted to flexural bending do not significantly shift in frequency due to acceleration of the shear wave upper the neutral line of deformation and the deceleration of the shear wave under this line. The creation of a cavity near the neutral line allows to only accelerate or decelerate shear waves, yielding a frequency shift.

We based our device fabrication on gold bonding with a lapping/polishing process to prepare wafer compound to different devices [1]. This process allows a collective manufacturing of sensors contrarily to classical approaches. It allows us to manufacture a BAW pressure sensor on $\mathrm{LiNbO}_{3}$ membrane as shown in fig.1. A gold thin layer $(200 \mathrm{~nm})$ is deposited first by sputtering on both $\mathrm{LiNbO}_{3}$ and silicon wafers. Both wafers then are bonded together via gold layer compression into an EVG bonding machine as

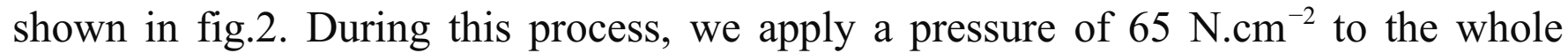
contact surface, yielding a high quality bond. $\mathrm{LiNbO}_{3}$ is subsequently thinned by lapping and polishing steps to an overall thickness of 100 microns. We finally seal the first stack with a structured silicon wafer to form cavity. Aluminum electrodes are deposited on the $\mathrm{LiNbO}_{3}$ upon the cavity to achieve working BAW resonators. 
Sensitivity of the final sensor to bending moments then is tested and results are compared to theoretical predictions.

\section{SENSOR DESCRIPTION}

The fabrication of Surface Acoustic Wave (SAW) pressure sensor based on membrane was strongly developed due to the wave frequency dependence versus tensile stress at the surface of the membrane when bent by pressure. In the case of Harmonic Bulk Acoustic Resonator (HBAR) propagating in such a membrane, the strain variations across the membrane thickness forbid the use of such an approach to develop pressure sensor applications. This can be easily demonstrated using for instance static finite element analysis with a very simple mesh as illustrated in fig. 1 Indeed, the strain and hence the stress change their signs along the membrane thickness, as shown in fig. 2. As a consequence, the strain variation across the HBAR generates velocity variations, on the one hand, the strain below the membrane neutral line yields an increase of resonant frequency of the HBAR, on the other hand, the strain above the neutral line yields a decrease of this frequency. Consequently, the resulting frequency shift is negligible.

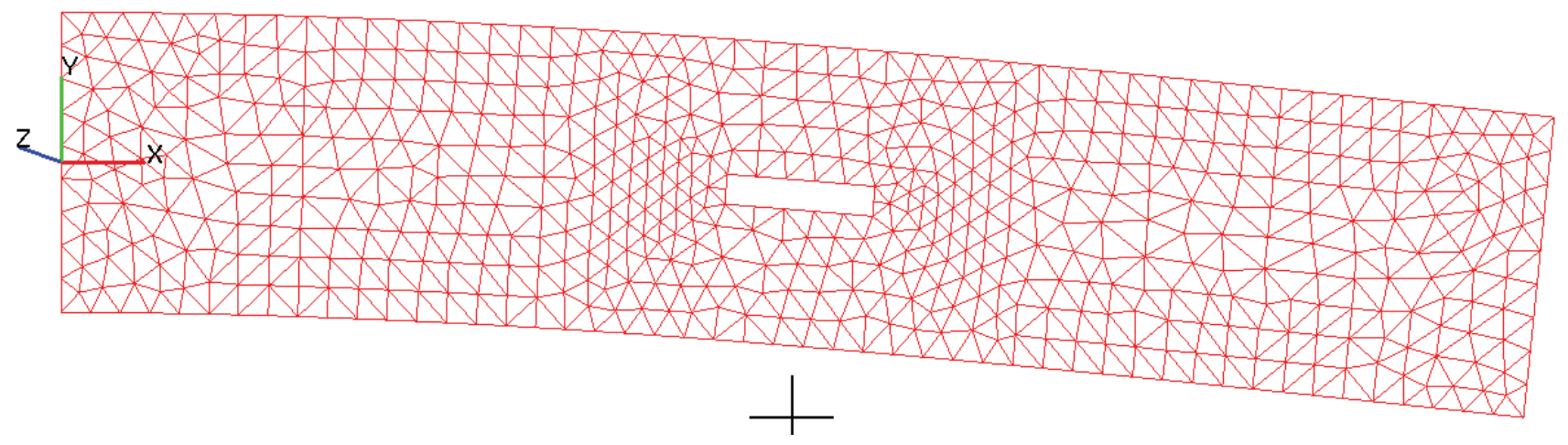

Fig. 1. Cantilever beam submitted to bending force simulated by static finite element analysis. The defect in the middle of the beam is used further in the proposed development.

In the case of a cantilever beam, one can imagine to manufacture a micro-cavity near the neutral line, without changing fundamentally its location. If the transducer of the HBAR structure is straight above this micro-cavity, the emitted bulk waves are reflected by this micro-cavity and hence confined in this membrane location. The micro-cavity then plays the role of a mirror for the waves, as illustrated in fig. 3 . The structure of such device is shown in fig. 4. First a standard HBAR structure is build and the defect located straight under the transducer location. This structure then is bonded on a plane wafer, yielding the expected material stack. The surface of the cavity should at minimum coincide strictly to the surface of the transducer, but to ease the fabrication (particularly to manage alignment issues) the cavity largely covers the transducer aperture. 


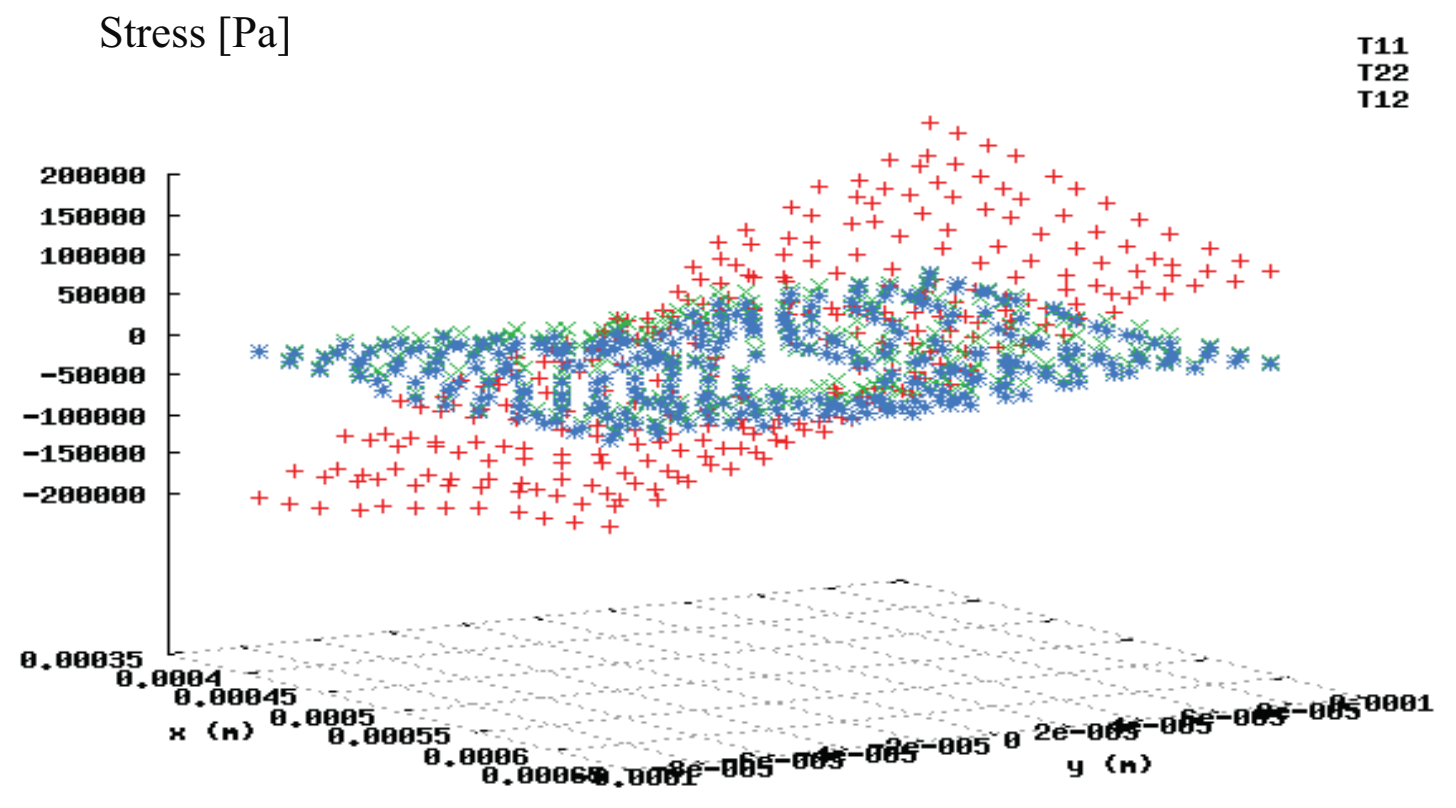

Fig. 2. Stress variations as a function of the crystallographic direction.

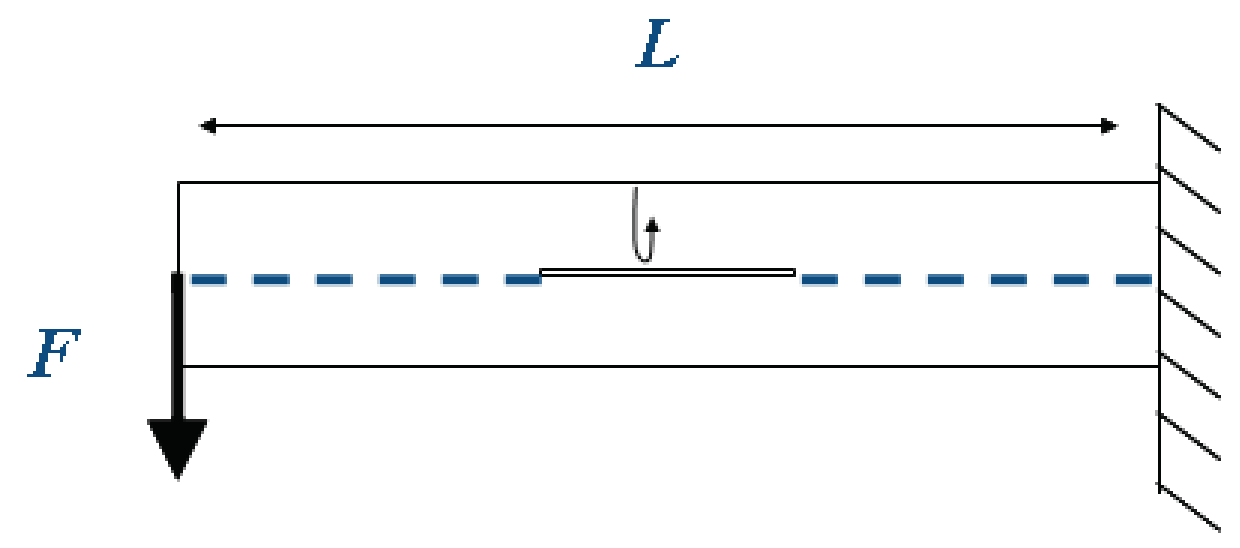

Fig. 2. Waves and neutral line behaviors in the case of cantilever with micro-cavity and HBAR built above it.

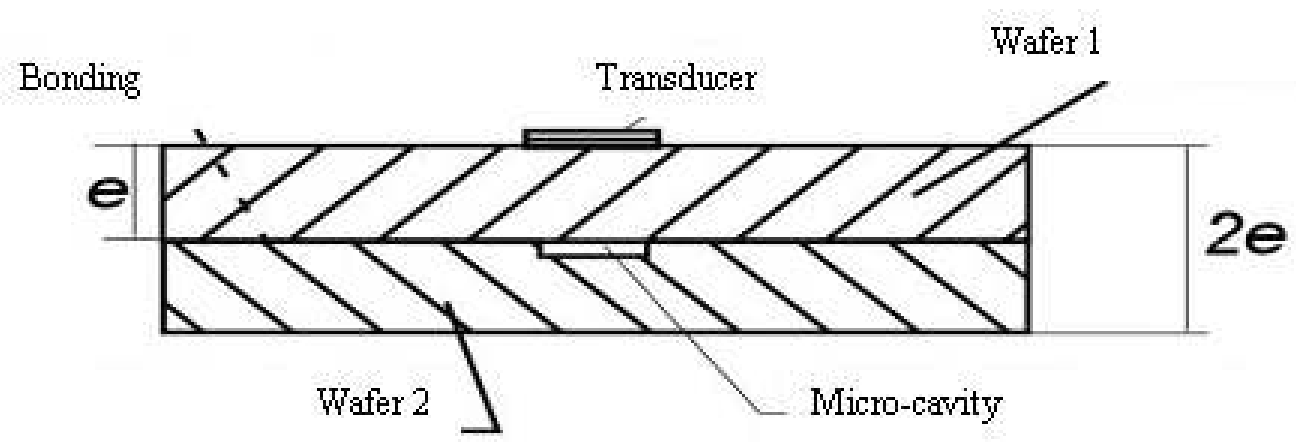

Fig. 3. Archetypal structure of the device (the micro-cavity surface coincides at minimum with the transducer aperture) 


\section{PROCESS FLOW}

The process flow-chart reported in fig. 4 allows one for a collective manufacturing of the HBAR-based sensors previously described. As explained in Introduction, we use thinned single-crystal piezoelectric materials and Silicon combined with a room temperature $\mathrm{Au} / \mathrm{Au}$ bonding technique to achieve the elementary HBAR structure. As shown below, a supplementary bonding operation is required to manufacture the sensor. More details are reported hereafter to explain the implemented approach.

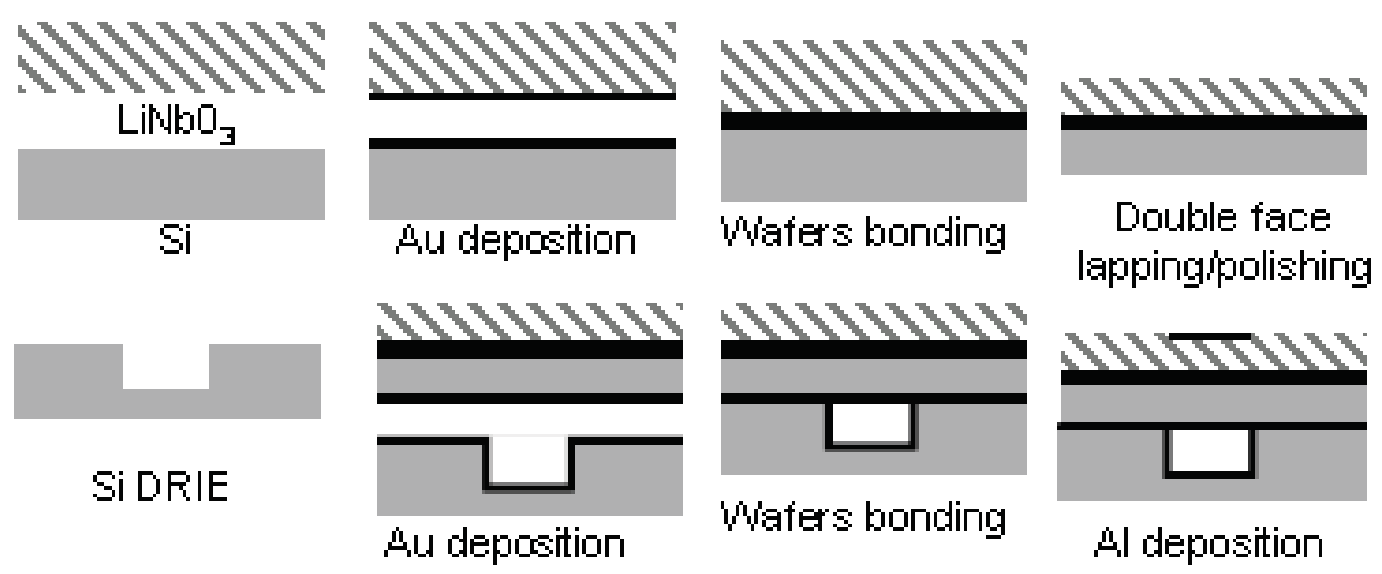

Fig. 4. Process flow-chart for the fabrication of the HBAR pressure sensor

\section{Single-crystal wafer bonding}

\section{Description of the process}

We based our process on the bonding of two single-crystal wafers. In this approach, we use optical quality polished surfaces to favor the bonding of the wafers. We start by a Chromium and Gold thin layer deposition by sputtering on both $\mathrm{LiNbO}_{3}$ and Silicon wafers. The $\mathrm{LiNbO}_{3}$ wafer is then bonded onto the Silicon substrate via the thermomechanical compression of the 200nm thick gold layers into an EVG wafer bonding machine as shown in fig. 5. During the bonding process, we heat the material stack at a

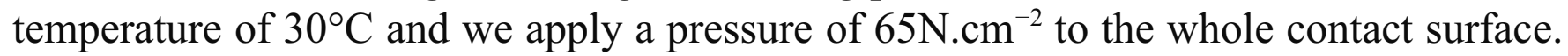
The bonding can be particularly controlled by adjusting the process duration and various parameters such as the applied pressure, the process temperature, the quality of the vacuum during the process, etc. We actually restrict the process temperature near a value close to the final thermal conditions seen by the device in operation. Since Silicon and $\mathrm{LiNbO}_{3}$ materials have different thermal expansion coefficients, one must account for differential thermo-elastic stresses when bonding both wafers and minimize them as much as possible. 


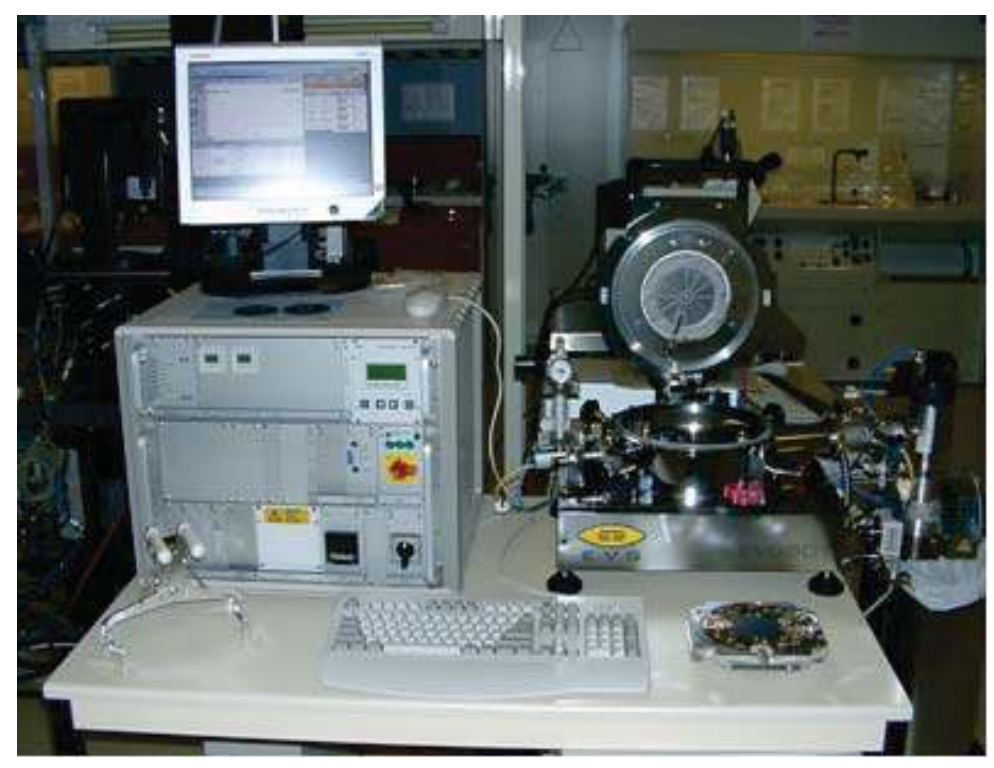

Fig. 5. Wafer Bonder EVG

\section{Ultrasonic Characterization of the bounding interface}

Once the bonding achieved, it is necessary to characterize the quality of the bonding. Due to the thickness of the wafers and the opacity of the stack (metal layers, Silicon), optical measurements are poorly practicable. As we want to avoid destructive controls of the material stack, ultrasonic techniques have been particularly considered here. The reliability of the bonding then is analyzed by ultrasonic transmission in a liquid environment. The bonded wafers are immersed in a water tank and the whole wafer stack surface is scanned. Figure 6 presents a photography of the bench. Two focalized transducers are used as acoustic emitter and receiver. They are manufactured by SONAXIS with a central frequency close to $50 \mathrm{MHz}$, a $19 \mathrm{~mm}$ active diameter and a $30 \mathrm{~mm}$ focal length. The beam diameter at focal distance at $-6 \mathrm{~dB}$ is about $200 \mu \mathrm{m}$.

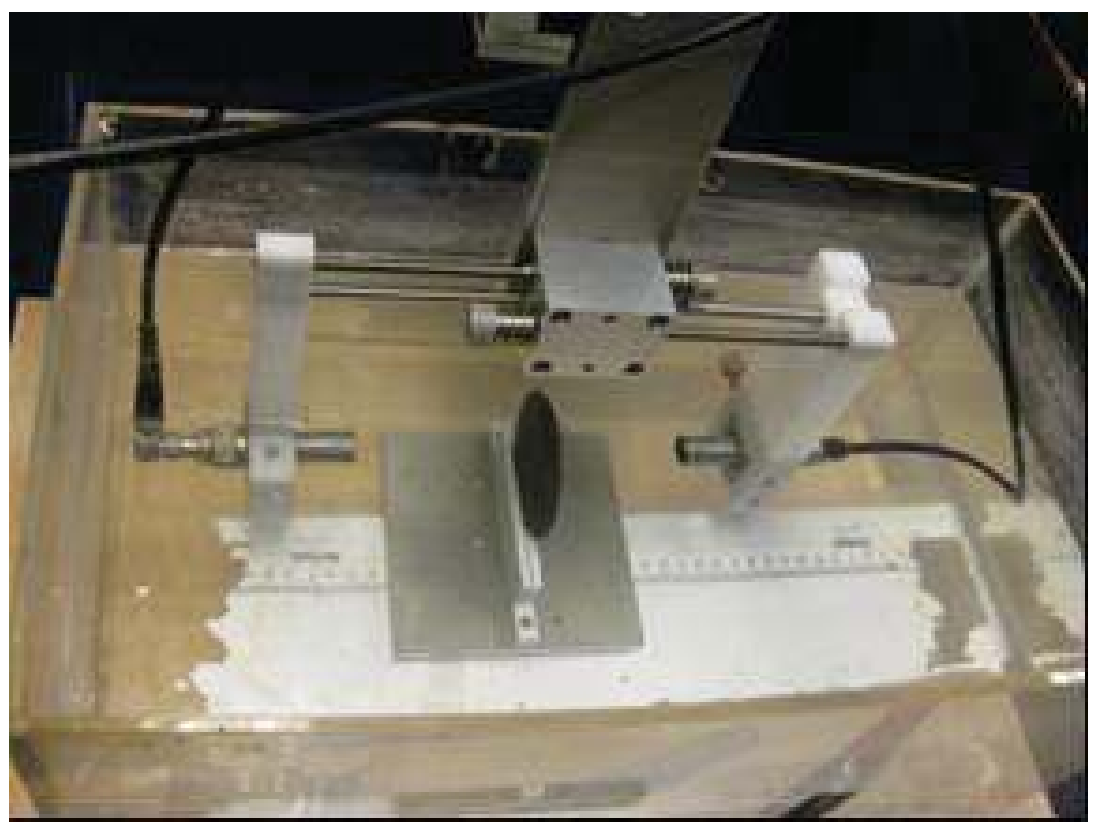

Fig. 6. Ultrasonic characterization bench dedicated to non destructive control of the bonding interface 
Such a lateral resolution enables one to detect very small defects. The principle of the characterization method is based on the measurement of the received acoustic amplitude which depends on the variation of the acoustic impedance of the bonding area. If the bonding presents a default at the interface between the two wafers, a dust or an air gap in most cases, the reflection coefficient of the incident wave is then nearly 1. The amplitude of the received wave is strongly reduced or even vanishes. Figure 7 shows a C-Scan of a Silicon/ $/ \mathrm{LiNbO}_{3}$ wafer bonding characterization. The blue color corresponds to bonded surfaces, whereas yellow and green regions indicate bonding defects.

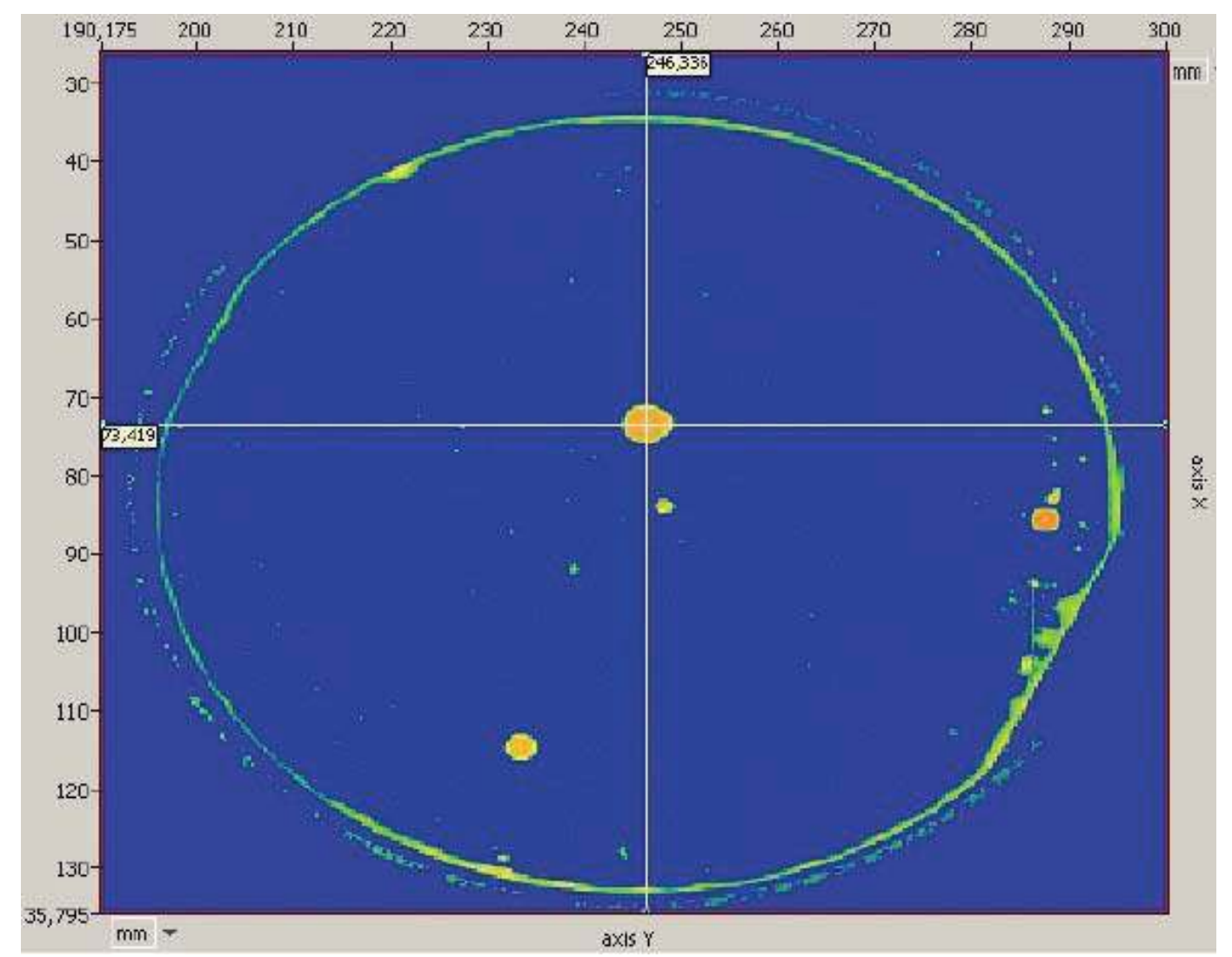

Fig. 7. Characterization of a Silicon/ $/ \mathrm{LiNbO}_{3}$ bonding - surfaces are bonded at $95 \%$

This method presents three major advantages:

- The control of the bonding can be made during the polishing steps without destruction; or the control can be done at the end of the process, indeed, the different layers obtained by sputtering do not disturb the measure.

- There is no constraints related to time resolution as in pulse-echo method, as the wafer thickness are not dramatically larger than the wavelength.

- The analysis of the ultrasonic transmitted signals is very simple because only the amplitude of the first detected signal contains the useful information.

\section{Lapping/Polishing}

The piezoelectric wafer is subsequently thinned by lapping step to an overall thickness of 100 microns. The lapping machine used in that purpose and shown in fig. 8 is a SOMOS double side lapping/polishing machine based on a planetary motion of the wafers (up to 4" diameter) to promote abrasion homogeneity. We use an abrasive 
solution of silicon carbide. We can control the speed of the lapping by choosing the speed of rotation, the load on the wafer, the rate of flow or the concentration of the abrasive. It is then followed by a micro-polishing step. This step uses a similar equipment dedicated to polishing operation and hence using abrasive solution with smaller grain.

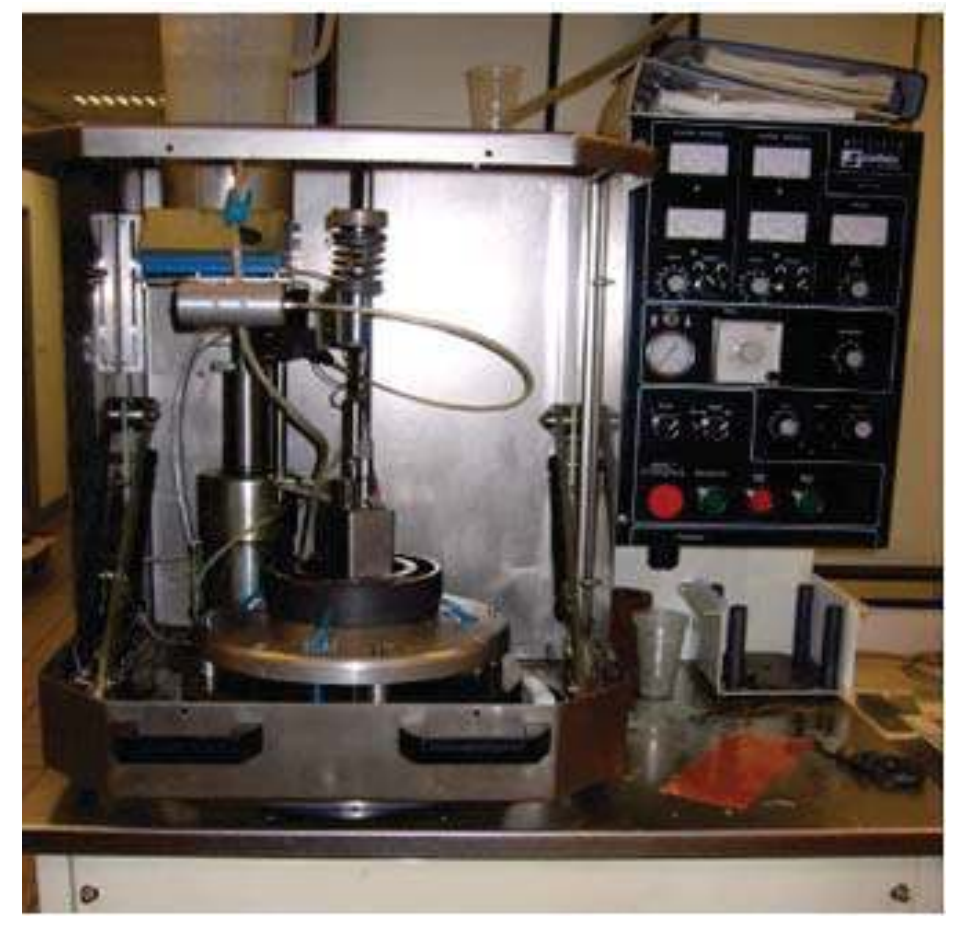

Fig. 8. SOMOS lapping/polishing machine.

\section{Micro-cavity fabrication}

We finish the process with a Deep RIE to etch a third silicon wafer to form the microcavity. We bond again this last wafer to the HBAR structure using the above described $\mathrm{Au} / \mathrm{Au}$ process. Once this last bonding achieved, aluminum electrodes are deposited on the thinned $\mathrm{LiNbO}_{3}$ plate surface with a lift-off process. This top electrode allows for connecting the HBAR-based sensor and for characterization operations.

\section{ELECTRICAL RESULTS}

We use a bench which allows us to apply different mass at the back of the HBAR sensor near the micro-cavity location. Figure 9 shows this bench first developed to characterize SAW sensitivity to stress effects. The device is wire-bonding to SMA connector to plug it to our Rohde\&Schwarz ZVR network analyzer. Once connected, the sensor is loaded by metallic disks of calibrated mass and the reflection coefficient $\mathrm{S}_{11}$ is recorded to characterize the device stress sensitivity. Figure 9 illustrates this experiment process and electrical response are reported in fig. 10 

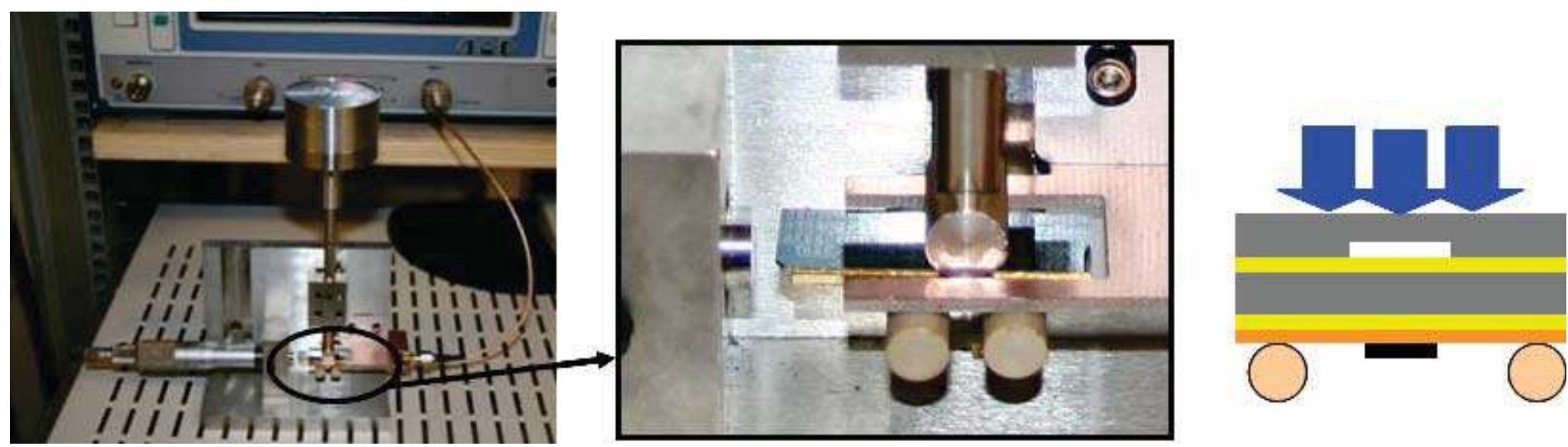

Fig. 9. Photos and principle scheme of the mechanical bench for stress sensitivity characterization

Electrical responses as a function of applied mass shows a shift of the resonance frequency of the HBAR. Figure 10 shows the electrical results and the shift of frequency vs mass loading on the device.
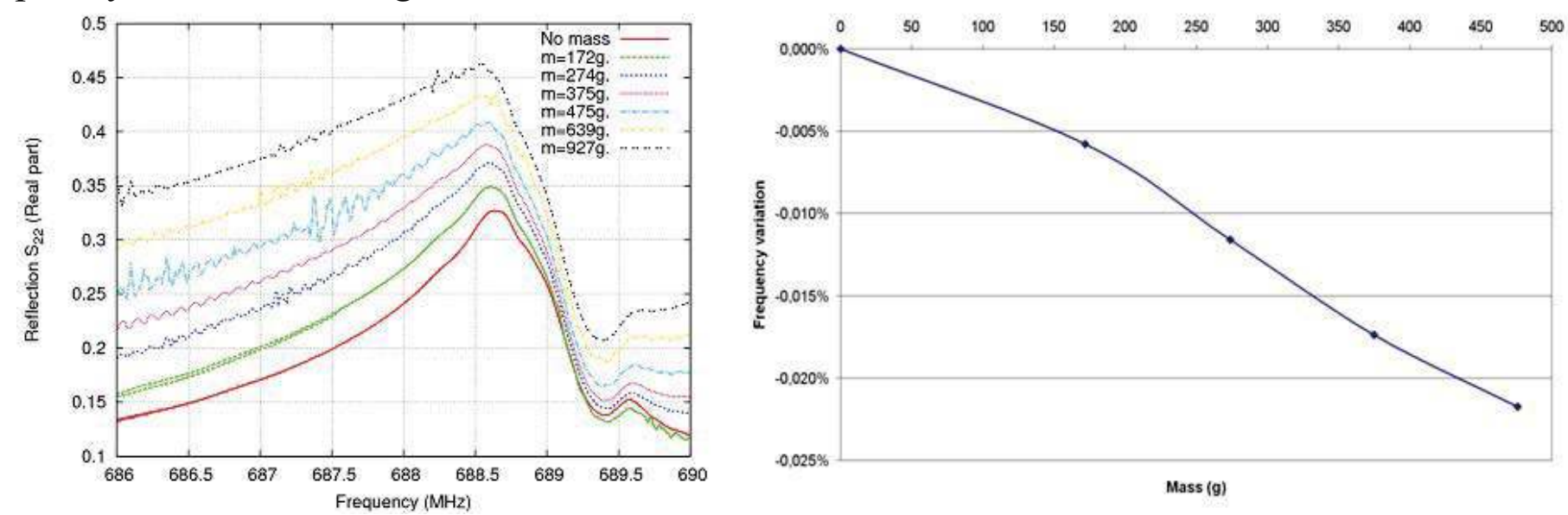

Fig. 9. Electrical results: $S_{11}$ magnitude variations vs. applied mass.

\section{CONCLUSION}

In this paper, we have proposed a new concept for pressure and more generally stress sensors exploiting single-crystal based HBAR. After describing the operation principle, the practical feasibility of the sensor has been shown, yielding electrical results allowing a first characterization of such sensor sensitivity. The process flow is generic and allows us to develop different devices such as HBAR or SAW sensors with the freedom of choosing material in function of the design requirements. Although the first reported results can not exploit the high quality resonance of such HBARs, more effort will be performed in the next future to definitely validate the approach and the corresponding stress sensitivity.

\section{REFERENCES}

[1] D. Gachon, E. Courjon, G. Martin, L. Gauthier-Manuel, J.-C. Jeannot, W. Daniau, S. Ballandras, Fabrication of High Frequency Bulk Acoustic Wave Resonator Using Thinned Single-Crystal Lithium Niobate Layers, Ferroelectrics, vol. 362, pp. 30-40, 2008 